\title{
How customer relationship management influences making better decisions
}

\author{
Fatemeh Izadi Manesh and Somayeh Hozouri*
}

Department of Management, Islamic Azad University, South Tehran Branch, Tehran, Iran

\begin{tabular}{l}
\hline C H R O N I C L E \\
\hline Article history: \\
Received May 12, 2013 \\
Received in revised format \\
12 August 2013 \\
Accepted 28 September 2013 \\
Available online \\
October 12013 \\
\hline Keywords: \\
Customer relationship \\
management \\
Banking industry \\
Factor analysis
\end{tabular}

\section{Introduction}

Ko et al. (2008) identified the status of Customer Relationship Management (CRM) adoption and explored the effect of organizational characteristics on the CRM adoption process in the Korean fashion industry. Using Rogers' innovation decision process model as the conceptual basis, they surveyed 94 Korean fashion firms to study the persuasion, decision, and implementation stages of CRM adoption. In this study, organizational variables included firm characteristics such as size, and strategy, product characteristics including category, fashion position as well as seasonality and CEO characteristics including age and education. The most frequently implemented CRM technology was the development of a customer database, whereas the mostly frequently mentioned advantages of CRM were encouraging repurchase. Moreover, respondents' perceptions of CRM benefits influenced CRM adoption, affecting the implementation of different CRM technologies (Wu \& Li, 2011; Shafia et al., 2011). Alshawi et al. (2011) tried to identify the organisational, technical and data quality

\begin{abstract}
Customers are the primary sources of making appropriate decisions and their feedbacks normally help us improve the quality of systems. In this paper, we present an empirical study to detect important factors influencing managers of banking industry make better decisions. The proposed study designs a questionnaire in Likert scale consists of 32 questions, distributes it among some bank managers. Cronbach
alpha is calculated as 0.805. In addition, Kaiser-Meyer-Olkin Measure of Sampling Adequacy and Approx. Chi-Square are 0.701 and 1675, respectively. Based on the results of our survey, we have derived nine factors including customers' welfare strategy, systems integration, organizational culture assessment, corporate strategies, organizational development, intelligence data strategies, supporting strategies, resource planning as well as research and development.
\end{abstract}


related factors impacting CRM adoption by SMEs. They reported that factors influencing the adoption of CRM in SMEs were largely similar to the factors influencing CRM adoption in previously studied other kinds of organisations. Garrido-Moreno and Padilla-Meléndez (2011) examined the relationships between knowledge management (KM) and CRM success using a structural equation model. They reported that having knowledge management capabilities was not sufficient for the success of CRM, but there were other factors to consider. Organizational factors indeed influenced CRM success and they appeared to be intermediaries of the effect of other factors. Chang et al. (2010) applied some data from Korean firms, addressed the process concerning how CRM technology translates into business outcomes. They reported that marketing capability had mediated the association between CRM technology use and performance. Moreover, a customercentric organizational culture and management system facilitated CRM technology implementation. The study served not only to clarify the mechanism between CRM technology implementation and organizational performance, but also to create the CRM results in the Korean context.

Dong (2012) reported that decision execution mechanisms, including both vertical advocacy and horizontal coordination, could substantially contribute to CRM diffusion; vertical advocacy has a notably greater impact on CRM implementation and firm performance gains than horizontal coordination, which has a greater impact on process gains. Li and Mao (2012) investigated how effective internal sales management control was achieved through CRM implemented and why enhanced control was beneficial to firms, which are largely overlooked by the extant literature. They reported that CRM implementation strengthened formal control and informal control, simultaneously. Formal control was substantially boosted by enhanced outcome measurability and process visibility of sales work. CRM implementation also facilitated informal control, by serving as the carrier of new institutional processes and sales philosophy. Shim et al. (2012) detected association rules and sequential patterns from the transactions of VIPs, and the rules and patterns were utilized to developed CRM strategies for the online shopping mall. Öztaysi et al. (2011) presented a measurement tool for customer relationship management processes. Kim et al. (2012) explores the existing gap between actual bank CRM implementation and customers' expectations of those actions in association with customer retention applying a survey method. They reported that that an incompatibility existed between the interval of actual CRM implementation activities and customers' expectations of the interval. Wang and Feng (2012) extended the resource-based perspective to the context of CRM and intended to develop a measurement model of CRM capabilities. Sangle and Awasthi (2011) investigated consumer's expectations from mobile CRM services. Liu et al. (2012) quantified the value of Internet-based CRM applications and tried to identify the mechanisms underlying CRM value creation. They reported that the integration contributes more value in markets featuring higher product differentiation or lower entry costs. Vella and Caruana (2012) tried to understand service providers and their intentions to implement their organization's CRM technology. They identified perceived usefulness and perceived ease of use as key elements, which are critical in encouraging service providers' intention to use CRM systems. Bahrami et al. (2012) stated that information technology could be an improvement tool for CRM. Chuang and Lin (2013) investigated the roles of infrastructure capability and customer orientation in enhancing customer-information quality in CRM systems. Duffy et al. (2013) investigated the role of justice in buyer-supplier relationships.

\section{The proposed study}

This paper presents an empirical study to detect important factors influencing managers of banking industry make better decisions. The proposed study designs a questionnaire in Likert scale consists of 32 questions, distributes it among some bank managers. Cronbach alpha is calculated as 0.805 . In 
addition, Kaiser-Meyer-Olkin Measure of Sampling Adequacy and Approx. Chi-Square are 0.701 and 1675 , respectively. Table summarizes the results of our survey on communalities.

\section{Table 1}

The summary of communalities

\begin{tabular}{|c|c|c|}
\hline Variable & Initial & Extraction \\
\hline VAR00002 & 1.000 & .729 \\
\hline VAR00003 & 1.000 & .720 \\
\hline VAR00004 & 1.000 & .660 \\
\hline VAR00005 & 1.000 & .629 \\
\hline VAR00006 & 1.000 & .548 \\
\hline VAR00007 & 1.000 & .553 \\
\hline VAR00008 & 1.000 & .564 \\
\hline VAR00009 & 1.000 & .605 \\
\hline VAR00010 & 1.000 & .664 \\
\hline VAR00011 & 1.000 & .641 \\
\hline VAR00012 & 1.000 & .573 \\
\hline VAR00013 & 1.000 & .577 \\
\hline VAR00014 & 1.000 & .606 \\
\hline VAR00015 & 1.000 & .651 \\
\hline VAR00016 & 1.000 & .501 \\
\hline VAR00017 & 1.000 & .703 \\
\hline VAR00018 & 1.000 & .574 \\
\hline VAR00019 & 1.000 & .509 \\
\hline VAR00020 & 1.000 & .397 \\
\hline VAR00021 & 1.000 & .727 \\
\hline VAR00022 & 1.000 & .738 \\
\hline VAR00023 & 1.000 & .574 \\
\hline VAR00024 & 1.000 & .717 \\
\hline VAR00025 & 1.000 & .508 \\
\hline VAR00026 & 1.000 & .532 \\
\hline VAR00027 & 1.000 & .634 \\
\hline VAR00028 & 1.000 & .644 \\
\hline VAR00029 & 1.000 & .573 \\
\hline VAR00030 & 1.000 & .663 \\
\hline VAR00031 & 1.000 & .589 \\
\hline VAR00032 & 1.000 & .579 \\
\hline
\end{tabular}

As we can observe from the results of Table 1, all factors are well above the minimum acceptable level of 0.5 . Fig. 1 demonstrates the results of Scree plot.

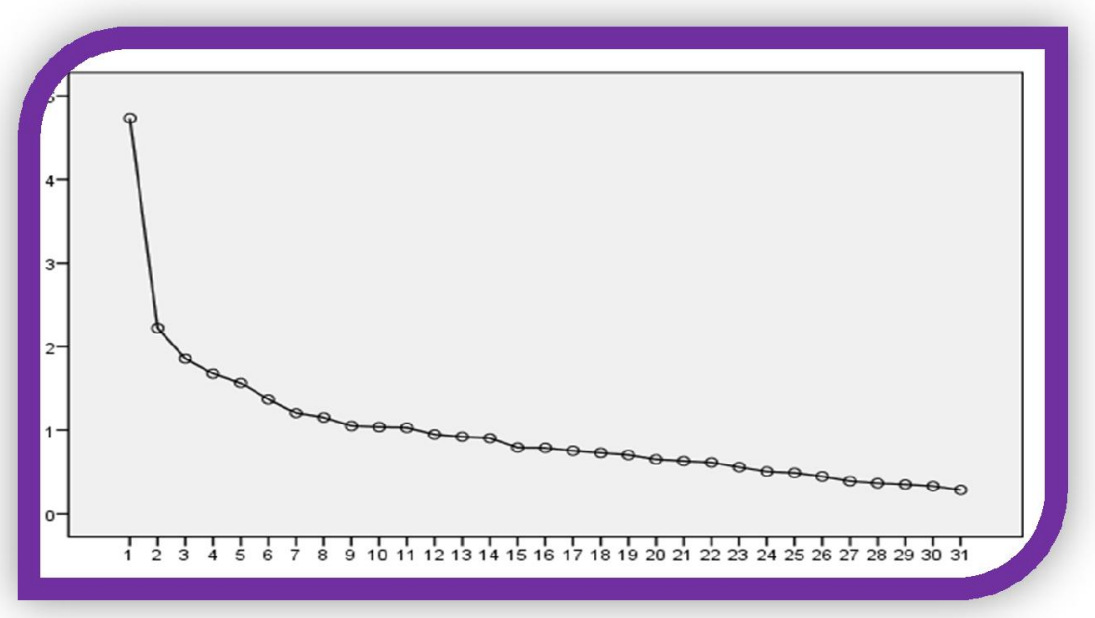

Fig. 1. The summary of Scree plot 
As we can observe from the results of Fig. 1, there are nine factors, which could be extracted for further studies. Table 2 demonstrates the results of factor analysis on these factors.

Table 2

The summary of principal component analysis after rotation

\begin{tabular}{|c|c|c|c|c|c|c|c|c|c|}
\hline \multirow[t]{2}{*}{ Component } & \multicolumn{3}{|c|}{ Initial Eigenvalues } & \multicolumn{3}{|c|}{ Extraction Sums of Squared Loadings } & \multicolumn{3}{|c|}{$\begin{array}{r}\text { Rotation Sums of Squared } \\
\text { Loadings }\end{array}$} \\
\hline & Total & $\begin{array}{c}\% \text { of } \\
\text { Variance }\end{array}$ & $\begin{array}{c}\text { Cumulative } \\
\%\end{array}$ & Total & $\begin{array}{c}\% \text { of } \\
\text { Variance }\end{array}$ & $\underset{\%}{\text { Cumulative }}$ & Total & $\begin{array}{r}\% \text { of } \\
\text { Variance }\end{array}$ & $\begin{array}{r}\text { Cumulative } \\
\%\end{array}$ \\
\hline 1 & 4.733 & 15.267 & 15.267 & 4.733 & 15.267 & 15.267 & 2.334 & 7.531 & 7.531 \\
\hline 2 & 2.220 & 7.162 & 22.428 & 2.220 & 7.162 & 22.428 & 2.098 & 6.769 & 14.299 \\
\hline 3 & 1.856 & 5.987 & 28.416 & 1.856 & 5.987 & 28.416 & 1.951 & 6.292 & 20.591 \\
\hline 4 & 1.677 & 5.409 & 33.824 & 1.677 & 5.409 & 33.824 & 1.935 & 6.241 & 26.832 \\
\hline 5 & 1.564 & 5.044 & 38.869 & 1.564 & 5.044 & 38.869 & 1.662 & 5.361 & 32.193 \\
\hline 6 & 1.368 & 4.413 & 43.281 & 1.368 & 4.413 & 43.281 & 1.641 & 5.294 & 37.487 \\
\hline 7 & 1.202 & 3.879 & 47.160 & 1.202 & 3.879 & 47.160 & 1.554 & 5.013 & 42.499 \\
\hline 8 & 1.148 & 3.705 & 50.865 & 1.148 & 3.705 & 50.865 & 1.516 & 4.890 & 47.390 \\
\hline 9 & 1.049 & 3.383 & 54.248 & 1.049 & 3.383 & 54.248 & 1.458 & 4.704 & 52.094 \\
\hline 10 & 1.036 & 3.342 & 57.589 & 1.036 & 3.342 & 57.589 & 1.387 & 4.476 & 56.569 \\
\hline 11 & 1.027 & 3.314 & 60.904 & 1.027 & 3.314 & 60.904 & 1.344 & 4.334 & 60.904 \\
\hline 12 & .947 & 3.055 & 63.958 & & & & & & \\
\hline 13 & .920 & 2.967 & 66.925 & & & & & & \\
\hline 14 & .903 & 2.912 & 69.837 & & & & & & \\
\hline 15 & .790 & 2.549 & 72.386 & & & & & & \\
\hline 16 & .786 & 2.536 & 74.922 & & & & & & \\
\hline 17 & .753 & 2.428 & 77.350 & & & & & & \\
\hline 18 & .727 & 2.346 & 79.696 & & & & & & \\
\hline 19 & .702 & 2.264 & 81.960 & & & & & & \\
\hline 20 & .649 & 2.093 & 84.053 & & & & & & \\
\hline 21 & .630 & 2.031 & 86.084 & & & & & & \\
\hline 22 & .612 & 1.974 & 88.058 & & & & & & \\
\hline 23 & .556 & 1.793 & 89.851 & & & & & & \\
\hline 24 & .503 & 1.622 & 91.473 & & & & & & \\
\hline 25 & .488 & 1.574 & 93.047 & & & & & & \\
\hline 26 & .444 & 1.433 & 94.480 & & & & & & \\
\hline 27 & .388 & 1.251 & 95.731 & & & & & & \\
\hline 28 & .363 & 1.171 & 96.903 & & & & & & \\
\hline 29 & .348 & 1.123 & 98.026 & & & & & & \\
\hline 30 & .329 & 1.060 & 99.087 & & & & & & \\
\hline 31 & .283 & .913 & 100.000 & & & & & & \\
\hline
\end{tabular}

Based on the results of our survey, we have derived nine factors including customers' welfare strategy, systems integration, organizational culture assessment, corporate strategies, organizational development, intelligence data strategies, support, resource planning and research and development.

\section{The results}

In this section, we present details of our findings on nine influencing factors.

\subsection{The first factor: customers' welfare strategy}

The first factor is associated with customers' welfare strategy. Table 3 shows details of our survey. As we can observe from the results of Table 3, "Evaluating customers' perspectives" is number one priority followed by "Detecting customers' preferences", "Awareness from the results of actions" and "Empowering employees". 
Table 3

The summary of factors associated with customers' welfare strategy

\begin{tabular}{llccc}
\hline Option & Factor weight & Eigenvalues & \% of variance & Accumulated \\
\hline Increase services for customers & .577 & & & \\
Empowering employees & .608 & & & \\
Detecting customers' preferences & .661 & 2.453 & 35.044 & \\
Evaluating customers' perspectives & .680 & & & \\
Awareness from the results of actions & .640 & & & \\
Encouraging flexibility & .543 & .383 & & \\
Applying internet & & & & \\
\hline Cronbach alpha $=0.68$ & & & & \\
\end{tabular}

\subsection{The second factor: Systems integration}

System integration is the second important factor and it includes seven factors, which are summarized in Table 4 as follows,

\section{Table 4}

The summary of factors associated with system integration

\begin{tabular}{lllll}
\hline \multicolumn{1}{c}{ Option } & Factor weight & eigenvalues & \% of variance & Accumulated \\
\hline Organizational development & .727 & & & \\
Rotation in jobs and job flexibility & .815 & 1.769 & 58.958 & 58.958 \\
Conflict management & .759 & & & \\
\hline Cronbach alpha $=0.65$ & & & &
\end{tabular}

According to the results of Table 4, "Rotation in jobs and job flexibility" is number one priority followed by "Conflict management" and "organizational development".

\subsection{Organizational culture assessment}

Organizational assessment is another important factor with three items summarized in Table 5.

\section{Table 5}

The summary of factors associated with organizational assessment

\begin{tabular}{lllll}
\hline \multicolumn{1}{c}{ Option } & Factor weight & eigenvalues & \% of variance & Accumulated \\
\hline Performance measurement & .707 & & & 53.001 \\
Justice within organization & .724 & 1.590 & 53.001 & \\
\hline Data mining applications & .752 & & & \\
\hline Cronbach alpha $=0.55$ & & & &
\end{tabular}

According to the results of Table 5, "Data mining applications" is the most important component in organizational assessment followed by "Justice within organization" and "Performance measurement".

\subsection{Corporate Strategies}

Corporate strategies are another important factors with four items summarized in Table 6 . According to the results of Table 6, "Knowledge management" is the most important component in organizational assessment followed by "Customer oriented organization culture", "Having a unified instruction" and "Outsourcing mechanisms". 


\section{Table 6}

The summary of factors associated with corporate strategies

\begin{tabular}{lcccc}
\hline \multicolumn{1}{c}{ Option } & Factor weight & eigenvalues & \% of variance & Accumulated \\
\hline Having a unified instruction & .664 & & & 45.064 \\
Knowledge management & .722 & 1.803 & 45.064 \\
Customer oriented organization culture & .716 & & \\
Outsourcing mechanisms & .572 & & \\
\hline Cronbach alpha $=0.55$ & & & &
\end{tabular}

\subsection{Organizational development}

Organizational development are another important factors with three items summarized in Table 7. According to the results of Table 7, "Knowledge management" is the most important component in organizational development followed by "Having a unified instruction", and "Customer oriented organization culture".

Table 7

The summary of factors associated with organizational development

\begin{tabular}{lcccc}
\hline \multicolumn{1}{c}{ Option } & Factor weight & eigenvalues & \% of variance & Accumulated \\
\hline Having a unified instruction & .750 & & & \\
Knowledge management & .806 & 1.729 & 57.625 & 57.625 \\
Customer oriented organization culture & .718 & & & \\
\hline Cronbach alpha $=0.63$ & & &
\end{tabular}

\subsection{Intelligence data strategies}

Intelligence data strategies are another important factors with two items summarized in Table 8. According to the results of Table 8, "Re-designing business activities" is the most important item followed by "Information and communication technology".

\section{Table 8}

The summary of factors associated with Intelligence data strategies

\begin{tabular}{lcccc}
\multicolumn{1}{c}{ Option } & Factor weight & eigenvalues & \% of variance & Accumulated \\
\hline Information and communication technology & .787 & & & \\
Re-designing business activities & .789 & 1.239 & 61.956 & 61.956 \\
\hline
\end{tabular}

Cronbach alpha $=0.48$

\subsection{Supporting activities}

Supporting activities are another important factors with two items summarized in Table 9. According to the results of Table 9, "Management of unpredicted events" is the most important item followed by "Integrated systems".

Table 9

The summary of factors associated with corporate strategies

\begin{tabular}{lcccc}
\hline \multicolumn{1}{c}{ Option } & Factor weight & eigenvalues & \% of variance & Accumulated \\
\hline Integrated systems & .814 & & & \\
Management of unpredicted events & .818 & 1.326 & 66.278 & 66.278 \\
\hline Cronbach alpha $=0.49$ & & &
\end{tabular}

\subsection{Resource planning}

Resource planning is another important factor with three items summarized in Table 10. According to the results of Table 10, "Cost/benefit analysis" is the most important item followed by "Organizational control" and "Reduce on job rotation among good employees". 
Table 10

The summary of factors associated with resources and control strategies

\begin{tabular}{lcccc}
\hline \multicolumn{1}{c}{ Option } & Factor weight & eigenvalues & \% of variance & Accumulated \\
\hline Organizational control & .705 & & & \\
Reduce on job rotation among good employees & .530 & 1.321 & 44.025 & 44.025 \\
Cost/benefit analysis & .737 & & & \\
\hline
\end{tabular}

Cronbach alpha $=0.49$

\subsection{Research and development}

Research and development is the last important factor with three items summarized in Table 11. According to the results of Table 11, "Human resource management" is the most important item followed by "Technology" used to develop organizational objectives.

Table 11

The summary of factors associated with research and development

\begin{tabular}{lccccc}
\hline \multicolumn{1}{c}{ Option } & Factor weight & eigenvalues & $\%$ of variance & Accumulated \\
\hline Human resource management & .705 & & & \\
Technology & .530 & 1.321 & 44.025 & 44.025 \\
\hline Cron
\end{tabular}

\section{Conclusion}

In this paper, we have presented an empirical investigation for business development in banking industry. The proposed study of this paper has implemented principal component analysis and has detected 9 important factors. The study has implemented among some Iranian banks and the study has determined that integrated systems, management of unpredicted events as well as Knowledge management are among the most influencing factors in having better organizations. We believe the results of this study could be extended for other service industries and we leave it as a future research for interested researchers.

\section{Acknowledgment}

The authors would like to thank the anonymous referees for their construction comments on earlier version of this work.

\section{References}

Alshawi, S., Missi, F., \& Irani, Z. (2011). Organisational, technical and data quality factors in CRM adoption-SMEs perspective. Industrial Marketing Management, 40(3), 376-383.

Bahrami, M., Ghorbani, M., \& Arabzad, S. M. (2012). Information Technology (IT) as An Improvement Tool For Customer Relationship Management (CRM). Procedia-Social and Behavioral Sciences, 41, 59-64.

Chang, W., Park, J. E., \& Chaiy, S. (2010). How does CRM technology transform into organizational performance? A mediating role of marketing capability. Journal of Business Research, 63(8), 849855.

Chuang, S. H., \& Lin, H. N. (2013). The roles of infrastructure capability and customer orientation in enhancing customer-information quality in CRM systems: Empirical evidence from Taiwan. International Journal of Information Management, 33(2), 271-281. 
Dong, S. (2012). Decision execution mechanisms of IT governance: The CRM case. International Journal of Information Management, 32(2), 147-157.

Duffy, R., Fearne, A., Hornibrook, S., Hutchinson, K., \& Reid, A. (2013). Engaging suppliers in CRM: The role of justice in buyer-supplier relationships. International Journal of Information Management, 33(1), 20-27.

Garrido-Moreno, A., \& Padilla-Meléndez, A. (2011). Analyzing the impact of knowledge management on CRM success: The mediating effects of organizational factors. International Journal of Information Management, 31(5), 437-444.

Kim, M., Park, J. E., Dubinsky, A. J., \& Chaiy, S. (2012). Frequency of CRM implementation activities: a customer-centric view. Journal of Services Marketing, 26(2), 83-93.

Ko, E., Kim, S. H., Kim, M., \& Woo, J. Y. (2008). Organizational characteristics and the CRM adoption process. Journal of Business Research,61(1), 65-74.

Li, L., \& Mao, J. Y. (2012). The effect of CRM use on internal sales management control: An alternative mechanism to realize CRM benefits. Information \& Management, 49(6), 269-277.

Liu, A. Z., Liu, H., \& Xu, S. X. (2012). How do competitive environments moderate CRM Value?. Decision Support Systems.

Öztaysi, B., Sezgin, S., \& Özok, A. F. (2011). A measurement tool for customer relationship management processes. Industrial Management \& Data Systems, 111(6), 943-960.

Rogers, E.M. (1995). Diffusion of innovation. New York: Free Press; 1995.

Sangle, P. S., \& Awasthi, P. (2011). Consumer's expectations from mobile CRM services: a banking context. Business Process Management Journal,17(6), 898-918.

Shafia, M. A., Mazdeh, M. M., Vahedi, M., \& Pournader, M. (2011). Applying fuzzy balanced scorecard for evaluating the CRM performance. Industrial Management \& Data Systems, 11 1(7), 1105-1135.

Shim, B., Choi, K., \& Suh, Y. (2012). CRM strategies for a small-sized online shopping mall based on association rules and sequential patterns. Expert Systems with Applications, 39(9), 7736-7742.

Vella, J., \& Caruana, A. (2012). Encouraging CRM systems usage: a study among bank managers. Management Research Review, 35(2), 121-133.

Wang, Y., \& Feng, H. (2012). Customer relationship management capabilities: Measurement, antecedents and consequences. Management Decision, 50(1), 115-129.

Wu, S. I., \& Li, P. C. (2011). The relationships between CRM, RQ, and CLV based on different hotel preferences. International Journal of Hospitality Management, 30(2), 262-271. 